\title{
Mental Maps and the Use of Sensory Information by Blind and Partially Sighted People
}

\author{
Marion Hersh \\ Biomedical Engineering, University of Glasgow, Glasgow G12 8LT, Scotland, \\ marion.hersh@glasgow.ac.uk
}

\begin{abstract}
The paper aims to fill an important gap in the literature by reporting on blind and partially sighted people's use of spatial representations (mental maps) from their perspective and when travelling on real routes. The results presented here were obtained from semi-structured interviews with 100 blind and partially sighted people in five different countries. They are intended to answer three questions about the representation of space by blind and partially sighted people, how these representations are used to support travel and the implications for the design of travel aids and orientation and mobility training. They show that blind and partially sighted people do have spatial representations and that a number of them explicitly use the term mental map. The paper discusses the variety of approaches to spatial representations, including the sensory modalities used, the use of global or local representations and the applications to support travel. The conclusions summarise the answers to the three questions and include a two-level preliminary classification of the spatial representations of blind and partially sighted people.
\end{abstract}

Index Terms: blind, partially sighted, spatial representation, mental model, sensory information.

ACM CCS: user studies, transportation, people with disabilities, user characteristics, user models.

\section{Introduction}

The paper aims to fill an important gap in the literature by reporting on blind and partially sighted people's use of spatial representations (mental maps) from their perspective and when travelling on real routes. As will be discussed in sections 1.1 and 1.2, there is a body of research on cognitive mapping, which shows that blind people are able to form mental maps and make use of different types of sensory information to do this. There is also some discussion in the literature of the factors which affect the ability of individual blind people to form accurate mental maps and use them to support travel, as well as the value of (audio) tactile maps in doing this.

Many blind and partially sighted people are very successful (independent) travellers, though others rarely go out on their own. The ability to understand space and form representations of it generally makes an important contribution to the ability to travel unaccompanied to a desired destination and carry out additional activities en route. It is now recognised that representing space is not a purely visual activity and that vision is neither necessary nor sufficient on its own for spatial coding [Millar, 1988]. 
However, research on exactly how blind people use information from different sensory modalities to construct mental maps and what these maps look like is still lacking. There is also no real understanding of how blind and partially sighted people process spatial information. In addition, existing research has been based on experiments involving artificial scenarios and not on the construction of mental maps during actual travel and limited attention has been given to the perspectives of blind people.

Therefore, in addition to its value in itself, increased understanding of the spatial representations of blind people could be important for understanding the factors and reasons that determine whether blind and partially sighted people become successful unaccompanied travellers. The results could also make a useful input to improving orientation and mobility training and the design of travel aids for blind and partially sighted people.

This paper aims to contribute to filling these gaps and answering the following questions:

1. How do blind people represent space and what sensory modalities do they use to do this?

2. How do blind people use their spatial representations to support travel?

3. What are the implications of the responses for the design of travel aids and orientation and mobility training?

It does this by drawing on data obtained from semi-structured interviews with 100 blind and partially sighted people in five different countries, as part of a wider project. The results show that blind and partially sighted people do have spatial representations and that a number of them explicitly use the term mental map. The paper discusses the variety of approaches to spatial representations, including the sensory modalities used, the use of global or local representations and the applications to support travel. The conclusions summarise the answers to the three questions and include a two-level preliminary classification of the spatial representations of blind and partially sighted people.

The paper is organised as follows. The remainder of section 1 presents a literature review. Methods are presented in section 2, results in section 3 and discussion and conclusions in section 4 . The results section is divided into five subsections based on major themes identified during the analysis.

Some of the material from other sections of the interviews has previously been published [Hersh, 2013ab, 2015, 2016]. There is also some overlap between the literature review and/or methods sections in this and Hersh [2009a, 2013ab, 2015, 2016]. However, the interview material presented in the results section has not previously been published and both the results and discussion and conclusions sections are being published for the first time.

The results presented here have their roots in [Hersh, 2009b], which is based on preliminary analysis of some of the earlier interviews. However, this is a conference tutorial rather than a research paper. Issues of spatial representations are 
developed to some extent in [Hersh, 2016] which discusses travel issues for deafblind people. This includes some discussion of the spatial knowledge of deafblind people, their spatial representations and their use of tactile maps and landmarks. However, these issues are one section of a paper and are consequently considered in much less depth than here. The other papers are less directly relevant. They consider cane use by late blind people [Hersh, 2015], the impact of stigma on assistive device on the use of mobility and communication assistive devices by deafblind people [Hersh, 2013a] and issues related to communication, independence and isolation of deafblind people [Hersh, 2013b].

\subsection{Cognitive or Mental Maps}

A cognitive or mental map is a mental construct which is used to learn, understand, simplify and explain the environment and human interactions with it [Kaplan, 1973, Walmsley et al., 1990]. It can support spatial thinking and communication about and discussion of spatial knowledge [Downs and Shea, 1977]. The term was first used by Tolman [1948] and there are several different definitions [Kitchin, 1994]. It frequently refers to very high-level spatial processing, involving a survey type representation of the environment, which allows efficient movement between places [Péruch et al, 2000], but can also cover route representations. Mental maps are frequently based on rectangular grids and a grid structure is one of their most useful 'mistakes' [Kuipers, 1978].

The process of obtaining a mental model is interactive [Downs and Stea, 1977] and movement, is considered necessary to link the external environment to the mental representation [Held and Rekosh, 1963]. There is generally some simplification and schematisation [Tversky, 2003] and the result need not be 'map-like'. Individual preferences frequently affect what is included and non-existent elements may be added as people assume their existence based on previous experience [Downs and Stea, 1977]. Mental maps may include information about object locations and spatial relations [Kaplan, 1976], observations, maps, route descriptions, fixed features, networks of streets and intersections and topological and metric relations [Kuipers, 1983]. They have a number of applications, including provision of the information required for spatial decision making [Briggs, 1973], aiding wayfinding and movement in the larger physical environment, preventing getting lost and organising (spatial) experience [Lynch, 1960; Siegel and White, 1975]. The cognitive maps of large and medium scale environments are particularly important, as they are adapted to support travel, initially related to travel plans and subsequently to their execution [Gärling et al., 1984].

While limited attention has been paid specifically to blind people in the literature on cognitive maps, most of the above information is equally relevant to them. The recognition of a distinction between the mental maps of familiar and unfamiliar areas, probably due to the collection and integration of information over time [Kuipers, 1983] may be particularly relevant to blind people. It has been suggested that the spatial relations in the mental maps of familiar environments are likely to be coherently organised, though metric information may not be correct, and that mental maps of unfamiliar environments are closer to a collage or 'thematic overlay of multimedia from different points of view' [Tversky, 1993]. Similarly, observation of area learning indicates the use of prominent landmarks in unfamiliar areas, but local 
features in familiar areas, where sufficient familiar routes are known to follow them without needing area orientation [Kuipers, 1978].

However, there is some research which indicates possible differences between the mental maps of blind and sighted people. This includes studies showing blind people's preference for egocentric (based on body coordinates) over allocentric (based on external coordinates) frames of reference e.g. [Corazzini et al., 2010] and route rather than survey representations [Thinus-Blanc and Gaunet 1997]. The importance of landmarks has been recognised [Millonig and Schechtner, 2007; Raubal and Winter, 2002], making it likely that they will be an important component of the mental maps of both blind and sighted people. In the case of blind people there is evidence from route descriptions of the importance of tactile and audio information to them [Kulyukin et al., 2008], making it likely that these elements feature prominently in their mental maps.

There are also indications from a small-scale study that the use of camera-based electronic travel aids can improve blind people's exploration strategies and help them develop more precise cognitive maps than with a long cane [Zeng et al., 2017].

\subsection{Amodality, Sensory Information and Cognitive Maps}

Research indicates that blind and sighted people have similar abilities to construct spatial mental models [Noordzij et al., 2006] and that these models are detailed and accurate for at least some blind people [Jaccobson, 1998]. Much of the research on the performance of spatial tasks supports the amodality hypothesis that spatial images are sense independent and visual experience is not required for spatial coding mechanisms [Guidice et al., 2009] rather than the alternative hypothesis of visual recoding [Lehnert and Zimmer, 2008; Newell et al., 2005]. For instance, verbal descriptions and visual representations have been shown to be equivalent in the sense of using the same processes, references, frames and geometric laws, though verbal descriptions generally provide less information [Bryant, 1997; Tinti et al., 2006]. Mean response times and pointing errors in haptic and visual learning of spatial layouts are nearly identical [Guidice et al., 2011]. Similar performance was obtained for locating targets using hearing, vision and mixed modalities, though vision was very slightly $(26 \mathrm{~ms})$ faster. When targets immediately followed each other the modality order made a difference, but this difference and the performance costs of modality switching disappeared when there was a slight time lag. This provides further support for amodality, at least for signals held in memory for a small amount of time and with at least a minimal time lag between targets of different sensory modalities [Loomis et al., 2012].

Several authors e.g. [Passini and Proulx, 1988, Spencer et al., 1989; Vecchi, 1998] have found that blind people are able to use auditory, tactile, movement, and other sensory cues to acquire, store, code and recover spatial information and move in and gain efficient knowledge of space. Additionally, proprioceptive information from walking the route can improve pointing accuracy, particularly for complex routes [Waller and Greenauer, 2007]. However, due to the different characteristics of the different sensory modalities, blind people generally require more time [Rieser et al., 1986] and cognitive effort [Byrne and Salter, 1983; Vecchi, 1998] than sighted people to obtain spatial information and carry out spatial tasks. A spatial model in 
the form of a set of procedural instructions may enable blind people to construct better mental models and do so more quickly than using a survey description [Noordzij et al., 2006].

Successful navigation requires blind people to have access to and be able to process spatial cues and sensorimotor information from different modalities [Halko et al., 2014; González-Mora et al., 1999]. Several studies have shown the usefulness of auditory devices [Ohuchi et al., 2006; González-Mora et al., 1999] and tactile maps, including with audio labels and beacons [Jacobson, 1998] in supporting route learning. However, despite some claims to also investigate the use of these devices in developing cognitive maps, they do not show how blind people use auditory and/or tactile information in forming mental maps or discuss the content and format of blind people's mental maps.

Tactile maps have been found to be a useful source of complex spatial information for blind and partially sighted people including in combination with direct experience in O\&M training [Espinosa et al., 1998; Ungar et al., 1993]. There are indications that blind people are better at acoustic localisation than sighted people. In particular, early blind people have been found to be faster and generally more accurate in detecting an auditory target from distractor sounds in a variety of conditions [Lerens and Renier, 2013]. Late blind people have been found to be able to use musical representations of buildings and other objects to recognise and describe them [Cronly-Dylon et al., 2000]. The authors suggest that the closeness of participants' drawings to the object represented indicates the formation of visual mental images. However, this will require further research. Multisensory applications, such as audio tactile maps, can be used by blind people to improve accuracy and detail and develop rich cognitive maps which may include streets, intersections and points of interest [Jacobson, 1998; Koukourikos and Papadopoulos, 2015].

Studies indicate that late blind and sighted people frequently have similar spatial abilities, whereas the spatial abilities of early/congenitally blind people are generally different from those of both these groups. Late blind and sighted participants have been found to obtain similar metric representations from verbal descriptions [Noordzij, 2006] and late blind participants to obtain representations with metric properties from spatial haptic and verbal information.

Both early and late blind people have been found to prefer route to survey descriptions, whereas sighted people generally preferred survey descriptions. For instance, they developed more effective mental maps and obtained more accurate comparisons of bird flight distances from route descriptions, whereas sighted participants performed better with survey descriptions. However, early blind people constructed less accurate mental models than sighted or late blind people, regardless of whether they used route or survey descriptions [Norrdzij et al. 2006]. Congenitally and late blind participants were able to use both verbal descriptions and movement in a large-scale immersive virtual environment in a real room to produce accurate mental spatial images, but blindfolded sighted participants were unable to produce precise spatial representations from movement. The authors have suggested that development of a metrically accurate representation of a spatial environment requires blind people to encode spatial information using the sensorimotor system [Afonso et al., 2010]. 
There are indications that both mobility skills and the strategies used affect the ability to process spatial descriptions. For instance, 'autonomous' blind travellers have been found to perform better than 'non-autonomous' ones and as well as sighted people when provided with either a survey or a route description. This seems to be related to the use of mental imagery strategies and greater experience of mobility. This indicates that the ability to produce spatial representation (and travel unaccompanied) could be improved by encouraging independent mobility and the use of mental imagery strategies [Schmidt et al., 2013].

Travel performance has also been found to be affected by the tactile map reading strategies used [Ungar et al., 1995]. Strategies which supported the development of mental representations and required environmental awareness facilitated spatial orientation and travel on unfamiliar routes, whereas memorising decisions led to more hesitations and deviations from the route [de Fatima et al., 2015]. Participants who used a combination of landmarks, route recognition and area knowledge were able to develop an ordered spatial representation, whereas the lack of one of these components led to more fragmented representations [de Fatima et al., 2015].

\subsection{Development of Electronic Mobility Aids}

Despite the development of a large number of technological solutions, the most popular aids are still the long cane and the guide dog. However, popularity of apps on mobile phones is increasing. Development of electronic aids has taken place in three overlapping phases [Pissaloux et al., 2016], with continuing development of new phase 1 and phase 2 devices, though the focus has shifted to phase 3 .

Phase 1 focused on obstacle detection devices with additional functionality. They were frequently in the form of a cane and detected obstacles at a height or a long distance e.g. the laser cane, the smart cane, the ultracane, the Tom Pouce and Télétact [Pissaloux et al., 2016], the EyeCane [Buchs et al, 2017] and electronic long cane [Hersh and García Ramírez, 2018]. Some of the more recent devices extract environmental information using cameras and signal processing algorithms [Pissaloux et al., 2016]. Other devices in this category include BBeep [Kayukawa et al.,2019], which detects people and admits an alert to encourage the detected person to avoid the user. A small number of aids combine obstacle avoidance and wayfinding/navigation functionality e.g. Stick for Environment Explorations [Yusro at al., 2013] and the multi-sensor electronic travel aid [Periasamy and Krishnapriya, 2019].

Phase 2 developed navigation and wayfinding devices using two main approaches with overlapping functionality [Hersh, 2009b]. Global navigation satellite systems, most commonly global positioning systems (GPS), locate the user. GPS systems have point of interest and other functions. Those useable by blind people include Trekker Breeze, Trekker GPS, Navigator and Captain and software such as wayfinder on a mobile device [Pissaloux et al., 2016]. Environmental information beacons locate a point in space using active or passive radio-frequency identification (RFID) tags or infrared transmitters [Fernandes et al., 2019] e.g. the Talking Signs system and the Haptic Pointer Interface [Pissaloux et al, 2016]. They may have additional functions. 
The current phase, phase 3 is developing apps to be used on smart mobile devices [Pissaloux et al., 2016] and vision sensors linked to smart mobile device. This has been made possible by developments in information and communication technology which have significantly increased their computing power. Many of the apps developed to date provide specific contextual information eg. Find my bus and Find my busstop which can be used by blind and sighted people. However, 3D vision sensors are increasingly being used in navigation, including on mobile devices [Fernandes et al., 2019]. Gharani and Karimi's [2017] context-aware system and two devices developed by Li et al. [2016, 2019] all use their integrated cameras in obstacle avoidance and navigation, outdoor and indoor respectively. Another recent development involves an indoor and outdoor object recognition and navigation system, which combines a smartphone with a camera and inertial measurement unit on a pair of spectacles [Bai et al., 2019]. A building information model has been developed for use with indoor navigation systems on mobile devices [Ivanov, 2017]. Mobile devices are also being used with cameras and signal processing to detect objects of particular types e.g. tactile tiles or surfaces [Ghilardi et al., 2016].

\section{Methodology}

This section summarises the methodology used. It is divided into two subsections, which consider participants and the approach based on semi-structured interviews respectively.

\subsection{Participants}

The results presented here were obtained from semi-structured interviews with 100 blind people, 20 each from France, Italy, Poland, Spain and the UK. They were selected from 300 blind people interviewed as part of a wider project [Hersh, 2009a, 2013ab, 2015]. The smaller sample was chosen to be male-female gender balanced and have a good distribution on demographic variables, such as age, age of onset of visual impairment and aid use, as shown in tables 1 and 2 . The original sample did not include participants with other genders than male and female. Several blind people from ethnic minorities or with additional impairments were included in the sample to increase diversity.

Table 1: Demographic information

Table 2: Visual impairment profile

Two further criteria for inclusion in the smaller sample were experiencing significant mobility barriers and experience of unaccompanied travel to increase the likelihood of including participants with experience of route learning and who did not mainly use sight in spatial exploration. This resulted in the inclusion of only a small number of non-aid users and fewer partially sighted than blind people, since they are less likely to experience barriers to mobility. The smaller sample also facilitated analysis of rich qualitative data. It included significantly greater numbers of cane than guide dog users, as is the case in the blind population. It should be noted that the data represents both total numbers and percentages and, due to rounding, numbers may not add to $100 \%$. 
Tables 3-7 in the appendix provide demographic information on the individual participants.

\subsection{Methods}

Semi-structured interviews were carried out by the author as part of a larger research project on travel issues for blind people. [Hersh, 2009a, 2013ab, 2015]. Participants were treated as experts on their own experiences and requirements. A semi-structured approach was used to provide both a framework to ensure all the topics of interest were covered and sufficient flexibility to allow exploration of issues raised by participants and the balance of time spent on different topics to be varied. The semi-structured approach also increased the likelihood of participants discussing their own experiences, opinions and preferences rather than reflecting back those of the researcher.

Contacts for interviews were obtained through organisations of or for blind people, rehabilitation centres, researchers working with blind people, recommendations by participants to potential participants and posts to forums used by blind and partially sighted people. In one case in response to seeing a post about the research a blind person contacted the author and asked if they would like her to organise people to be interviewed in their town. She subsequently assisted the author in recruiting participants in other parts of her country. Issues related to sampling disabled people are discussed in [Hersh, 2010, 2011] and will not be considered here.

The majority of interviews took place in the office of an organisation of blind people, and the remainder in another convenient location chosen by the participant, or by telephone. Interviews lasted between 30 minutes and three and a half hours, depending on factors such as the issues that arose and the participant's time availability. All the interviews on which this paper is based took place without an interpreter. In the majority of cases they were in the participant's language. In a few cases they were in the language of the participant's country of residence and in which they were fluent. This reduced the likelihood of misunderstandings and distortion. All the interviews and the subsequent analysis were carried out by a single researcher, who is the paper author. They are sufficiently fluent in the five languages to produce the interview schedule, carry out the interviews, carry out multilingual analysis and translate the chosen quotations.

Informed consent procedures in line with the requirements of the University of Glasgow and the British Psychological Society were used. A minimum participant age of 16 years was chosen, as the University of Glasgow plan for children is required for participants under this age. Information sheets were provided to participants electronically to ensure accessibility. In addition, participants were given the opportunity to ask questions about the research at the start of the interview and a further opportunity at the end. Consent was generally given orally rather than in writing, as this was more accessible to most of the participants. However, one of the Italian centres at which interviews took place also required compliance with its own ethics procedures and the use of written consent. In addition to consent to participate in the research, participants were asked to consent to the interviews being recorded. All the 100 participants on whose data this paper is based gave consent for their interviews to be recorded. However, four of the participants in the 
wider sample did not and the researcher took notes of their responses rather than recording them.

Participants were initially asked to introduce themselves and to talk about their lives, activities, interests, visual impairment and the role of travel in their lives. Topics arising from this introduction were then explored in more detail. Other topics covered, though not all topics were relevant to all participants, included: (i) the use of travel aids; (ii) orientation and mobility training; (iii) public transport, buildings and urban environments; (iv) spatial representations, description of a route and a familiar room or other space; (v) learning new routes, landmarks used and any changes in them due to changes in vision/visual impairment; (vi) any changes over time in their experiences of getting around; (vii) attitudes and support from family, friends and the local community; (viii) the communication strategies used by deafblind people; and (ix) education, employment, and interests.

The original interview schedule was produced in French, as France was the first country in which interviews were carried out. It was subsequently translated into other languages. The researcher/author considered it unnecessary to use back translation or other approaches to ensure that the five different language versions were identical, due to the nature of semi-structured interviewing. This means that there is already variation between the questions put to different participants and that the schedule may change over time. These variations were considered to be greater than any differences resulting from language issues. In addition, the use of a single researcher with all the participants helped to ensure consistency of approach.

In the case of the questions on spatial representations and mental maps, it was recognised that the term mental map would not necessarily be familiar to all participants and that some participants could have difficulties with the concept of spatial representations, which could seem very abstract. Therefore, participants were asked to describe a route and a familiar room or space as a more accessible approach to start obtaining this information. Where participants mentioned mental or cognitive maps this allowed the use of more direct questions. Other follow-up questions included the information about the senses used in obtaining and representing this information. Particular care was required in this section of the interviews, as some participants found the follow-up questions difficult. It was frequently necessary to rephrase questions while being alert for indications that participants did not wish to answer further questions on this topic. These issues were also explored in other sections of the interviews, both as follow-up questions, where appropriate, and as a result of participants providing relevant information in response to other questions.

The interviews took place over a period of about 18 months. During this time there were some changes in the details of particular topics. The relative importance of the section of spatial learning and mental maps increased over time. This was reflected in the relative time spent on these questions rather than changes in their formulation.

293 of the 300 interviews were recorded on a digital recorder and three on an analogue recorder. All the recordings were transcribed by a native speaker without translation. As already indicated, notes were taken of the remaining four, but they were not recorded. The analysis was based on transcript extracts identified using search terms related to route learning, sensory information and mental 
representations. The initial stage of open coding [Boeije, 2010] was carried out manually due to the multi-lingual nature of the material. An initial list of codes was obtained by coding a subset of the interview extracts in detail. These codes were then applied to all the interviews and additional codes added and applied.

Thematic analysis was then applied and a number of high and some lower level themes were obtained through analysis of the coded extracts. The approach had seven main stages. The first stage involved reading the 100 transcripts and noting the various themes related to route learning, cognitive mapping, spatial representations and the use of sensory information. As indicated above, the interviews were wide-ranging and therefore included other themes, such as education and employment. The second stage therefore involved identifying and extracting relevant sections of the transcripts. This involved using a wide range of search terms to locate relevant materials and then reading the transcript before and after the search term to identify relevant material. The aim at this stage was to remove materials not relevant to route learning, mental mapping, spatial representations and using sensory information, while not removing anything that could possibly be relevant. Therefore, the default position in the case of doubt was inclusion.

The third stage was combining these extracts into one document to facilitate coding, followed by reading this document and noting themes. The fourth stage involved preliminary coding of the document i.e. determining a code for each point or concept in it.

The fifth stage was investigating the codes, determining several high-level themes which covered these codes and reorganising the material according to these highlevel themes. This reorganisation made it very clear that there were two overarching themes: (i) route learning and (ii) spatial representations and the use of sensory information. The sixth stage therefore involved separating the material according to these two overarching themes. This division has resulted in this paper and a companion paper on route learning. At this stage sections of the transcripts relating to the chosen themes were translated into English by the author, trying to remain as faithful as possible to the style, spirit and meaning of the original. The author also referred back to the original language transcripts to verify translations and the context.

The seventh and final stage was carried out separately for each of the two overarching themes/papers. It involved more detailed analysis of each of the themes, including the identification of subthemes.

\section{Results}

The results are presented in the following five sections, based on important themes which were obtained from the initial thematic coding of the results. Further investigation of these themes when the paper was revised led to the identification of a number of major subthemes for each theme. These themes and subthemes have been used to structure the results section.

\subsection{Mental Maps and Their Applications}


Many participants developed a mental representation, frequently explicitly referred to as a mental map, of the routes and areas they were familiar with. As UK9 explained: 'especially if you've been once or twice you get a mental representation of the route.' Very familiar routes were very easily recalled in detail. UK12: 'Talking about the school grounds just now I have got a diagram of the whole grounds ... in my mind ... It really can become engrained like that.'

\subsubsection{Types of Mental Maps and Their Features}

Participants had various types of representations which could be characterised as realistic and schematic, with schematic representations typically in the form of plans or abstract. Some examples of these will be given in the following quotes. Several participants had schematic representations. These included representations based on straight lines or curves which were plan-like. ES14: 'I make a mental map in my head ... it is not an image, but like squares, straight lines or curves, but lines, not like a photo ... Before just the straight line and the plan.' Schematic representations could be abstract rather than map-like. UK12: 'It is nothing visual just being aware of a sort of an abstract diagram in the mind or one that you can sort of superimpose on your own memories. ... plus, just the general knowledge just thinking of it as a whole.' In some cases this abstract representation was not in the form of a diagram, but purely in the form of information. ES13: 'I have an idea, but not a plan in my head as I have not seen it on a plan .... information. Since I have not seen it, it does not have the perfection of a plan ... I understand, but do not process it in my mind as a plan.' The use of information in mental representations is discussed further in section 3.3. While this clarifies what is meant to some extent, further research could be useful. Realistic representations were less common, but included a plan with street names representing 'places as they are. FR3: 'It is a logical map. ... street names etc ... the representation ... in my head is a representation of places as they are.'

Participants also raised the difficulties and lack of need for exact mental representations. ES20: 'It is very difficult to make an exact representation of what you need to do on the route, to know the paces ... the crossings ... the turnings you need to make ... but it is not difficult to represent this in your head.'

Participants did not necessarily produce a one-off representation. Instead they were able to update it to take account of new information. ES8: 'when new features are introduced into a city ... you modify the mental image.'

Some participants placed themselves in the mental map. The examples given are based on using compass directions to determine their location. FR10: 'I place myself in the plan ... I try to place myself relative to north, south, east, west'. Another participant also used street orientations and illustrates the influence of orientation and mobility instructors in drawing up mental maps. PL13: 'My instructor used the concepts of parallel street, street at right angles and used (compass) directions. I think this is very good, much better than: at the back, to the right'.

One participant had created a store of fairly detailed route representations that they could take out and use when required. PL16: 'I draw myself a map in my head. I 
have compartments in my brain in which I stuff all the information on the theme of routes. When I need a particular route I take it out and remember what bus, how I walked, what the pavement was like ... and so on. I am good at this. ... [I compare with what is in my head] as I have a proposed route, but in reality there could be poles, kerbs, road works.' They found frequently used routes easier to access than those they had not used for a long time. PL16: 'The routes which I use every day are at the top, and at the bottom those I have used in the past. Taking out the route is sometimes easier, sometimes more difficult, depending on how deeply it is buried.'

\subsubsection{Applications of Mental Maps}

Many of the applications of mental maps result from their ability to provide a framework for organising travel information. This framework was very useful in providing preview and anticipation functions. During a journey sighted participants are able to use vision for these functions at least to some extent. However, blind participants are not and most travel aids are only able to do this to a limited extent. Several participants used a mental map as a means of organising information and giving them indications of what was coming. This included knowing what landmarks to expect, to enable them to check their location. IT13: 'It is not sufficient to just do a route, you have to keep it in your mind and then use the landmarks, I know that ... at a certain point the pavement widens and that tells me I have arrived ... at a certain point there is a telephone kiosk ... and I know I have reached the pavement of the bank.'

A related use of this organising and preview function was to help participants anticipate what was coming, which sighted people generally do visually. This gave them more time to consider appropriate actions and enabled them to decide on appropriate actions in advance. UK12: 'like thinking yourself through a map ... and just walking through it or sort of anticipating which path you are taking next ... anticipating what I would do if I was moving through it.' This preview facility could be helpful in avoiding problems, as it allowed participants to review particular journeys and make decisions based on the stored information. For instance, ES20: 'one day I may find that ... I realise I need to be careful as I remember that there was a problem between such and such a street and I better avoid it.' Participants therefore tried to remember particular features to support future journeys. The mental map provided a framework to make it easier to do this. ES18: 'I need to have a sort of mental map ... when I explore new places, I try to remember the road ... if there is a garden, something that particularly marks the road ... I keep it in my mind for the next time.'

Having a mental map made it much easier for participants to work out where they were on a route through comparing route information to their mental maps. This avoided the need for strategies with a high cognitive load, such as counting roads and buildings. ES8: 'This mental map allows me to know the number of roads ... buildings ..., because, as I am walking, I know where I am ... on what part of the route ... without needing to count anything.' A related application was avoiding getting lost. Participants considered mental representations essential for travelling effectively and avoiding getting lost. Having a mental representation also made it easier to travel to subsequent destinations. FR3: 'If you go to places without trying to make a mental representation you can get to your destination, but you will get lost faster and more easily and it will be more difficult to go somewhere else.' 
The next application is route planning. Mental maps were very helpful to enabling participants to choose the best route. This often took into account security as well as distance. IT18: 'I try to understand how to get there with the shortest journey, but the most secure one'. A related issue was route variation, which mental maps enabled some participants to do. FR10: 'I am able to change my route if I have a mental representation.'

One of the important travel strategies used by blind people is asking other people for information. In order to do this effectively and understand the responses, they require contextual information about the area around their destination or route. This contextual information could be provided by a mental map. ES17: 'Blind people need a very complete map in their heads ... otherwise you cannot ask ... move ... understand the relationship between two streets.'

\subsection{Global Representations and Details}

Many participants formed global representations of their routes. For instance, IT6: 'When I travel on a route I more or less have a global representation of it'. In some cases participants did not immediately form a global representation and this only happened once they knew the route really well. IT20: 'Once I have internalised a route ... I see the route to follow as a whole.' However, not all participants had global representations. For instance, FR2: 'I do not see it globally in my head'. This meant that some of the applications of mental maps, which required or were easier with global representations were not available to these participants. FR2:' I could not immediately see globally in my head if there is a shorter route'.

\subsubsection{Developing Global Representations}

The two approaches of starting with local and global representations will be considered first. Starting with local representations involved starting with details and then combining them to obtain a global representation using analysis followed by synthesis. FR10: 'You combine the information and construct a representation from it. ... You start with what you have discovered while travelling. It is always the same, analysis and then synthesis ... first the detail and then global.' The alternative approach involved starting with an incomplete global representation. Details and connections between components were added to give a fuller picture as travel provided additional information. IT6: 'At the start it is not a detailed representation ... but gradually as I do it, I remember the landmarks .... It is like a line which represents the route .... It follows the same route as I do, but is a global representation in terms of distance, more or less the number of times I have to turn, but is not very detailed

... later it fills up with the other details I use.' One participant made the useful analogy of developing a mental map to completing a puzzle. IT7: 'Gradually as I experience various routes I fill this map with other details, slowly as I understand where the squares are and put in the other streets ... I add the pieces as in a puzzle.' 
Other issues covered included the appropriate amount of detail. There were again two distinct perspectives. Several participants required very detailed representations, including a lot of landmarks. FR10: 'I need a lot of detail, textual details ... the name of the road I crossed ... I am on the right side of the street ... I need a lot of landmarks to know exactly where I am ... the movement of the route combined with the landmarks you find which enable you to know where you are. The landmarks are relative to the movement of the route.' This example is also useful in illustrating the type of details that could be included in a global mental map.

The other and opposite perspective was that too much detail could lead to cognitive overload, though many blind people learnt (complicated) routes by remembering details. ES17: 'There are people who learn a route in a very detailed way ... one detail after another and then need all the details. ... There are people who learn complicated routes like this. ... but when we start to go over our capacity to learn, then we go to simpler, less complex strategies, which resolve ... the problem.' However, the issue was not just the amount of detail, but how it was organised. In particular it was suggested that there were different levels and learning involved creating concepts from facts. ES17: 'I also think you learn to organise in levels ... first you learn the facts and then you start creating concepts'.

\subsubsection{Advantages and Applications of Global Representations}

This short section considers some of the advantages and applications of global representations. For instance, the ability to make the connections between different routes could give participants a much better understanding of the area. However, these connections frequently developed over time. FR3: 'Then I try to connect each area that I have been able to specify in a route ... Then I try to link the different routes ... sometimes I have for a long-time followed routes in the same area without connecting them, without knowing that they were two parallel routes.' It could also reduce tension when travelling. FR3: 'If I make this effort I will be more at ease on my routes.' The ability to see the global picture could be helpful in avoiding getting lost, presumably because it provided wider contextual information which made it easier to correct mistakes. FR3: 'I have some friends ... who get lost everywhere. I think they get lost because they think of things too locally ... I always try to generalise ... as without a global view you can make mistakes.'

\subsubsection{Combining Maps of Different Areas}

In addition to considering global and local representations, participants were often interested in combining the mental maps of two or more familiar areas, generally different parts of a city, in order to understand the connections between them and their relationship to the city as a whole. They had very varied degrees of success or the lack of it. However, some participants had a perspective of trying to understand the relationships between different areas and others focused solely on routes and areas of interest. In addition, some participants moved between or seem to share aspects of the two perspectives.

The issues involved in trying to combine the mental representations of separate areas will be considered first. Trying to bring together two separate plans was not easy. One of the French participants drew on the previously mentioned puzzle 
metaphor to illustrate the difficulties. FR10: 'in my head I try to bring together the two plans ... but it is complicated ... it is like a puzzle which I construct in my head with some slightly fuzzy pieces and some well-defined pieces.' Some participants were able to combine the representations of some areas and relate them to the whole city, but not to do this reliably for all city areas. PL4: 'I had an impression where different areas are, as though there were different maps, but I am not totally able to put them together. ... There are areas where I can do this. ... Then I can place the map properly in relation to the map [of the city].'

One of the participants discussed some of the difficulties involved in combining the representations of different areas. They noted that this is easier for areas with simpler layouts of parallel roads than those involving roads at an angle, where the relationships between them were more difficult to determine. FR10: 'there are parallel routes ... I construct squares in my head ... it is more difficult when there are diagonals ... at what angle ... when there are several directions round a square ... it is more difficult ... to remember the street order.' A mental map with a structured framework based on sections could facilitate determining the relationships between different areas, as well as adding further information. FR19: 'It is best to have a general [map] and then to divide it into sections ... so you can see the relationship of the whole and of one piece with another ... and this permits you to add more information.'

The other perspective involved focussing on areas of interest, such as the route to a particular destination or having more information about the home area than the city in general. For instance, participants frequently had mental representations of the areas they travelled through, but were unable to combine them to form a more global representation. PL12: 'I do not have an overall picture just the separate areas I have travelled through.' Another participant focused on their particular destination and was not interested in other areas. P15: 'when I go to a particular place I am not interested in the other parts.' However, this participant noted that their focus depended on the situation. P15: 'Whether I think [of the whole route or parts] depends on the situation.' Participants tended to pay greater attention to the details that were important for their journey and ignored others. PL4: 'when I go by bus ... I do not know it is facing west. ... I am starting to remember the turnings which are important for me. ... I know how areas are organised, what is next to what, but I do not know how the area looks.' This focus was a way of reducing unnecessary effort. PL4: 'If I have not seen it on a plan I do not want to spend 20 minutes concentrating to remember where and how it turned.' However, it should be noted that, as indicated above, this participant was able to combine their mental representations of some areas of the city.

\subsection{Representations Based on Auditory, Tactile and Other Sensory Information}

Blind people generally use all their available senses to obtain travel (and other) information. However, touch and hearing often had a particularly important role for participants.

\subsubsection{Tactile Representations}


Several participants had purely tactile representations, for instance IT7: 'audio no, tactile yes.' This section discusses the ways in which participants obtained tactile mental representations, including from touching a tactile plan, mock-ups to support travel or 3D tactile representations, and used the results, as well as the ability to speed up playing tactile mental representations.

Tactile mental representations could be developed from a tactile plan or mock-up they had touched. ES6: 'It is tactile ... as a result of working these roads ... in a plan ... in a mock-up ... and I remember this mock-up.' Another option was remembering the movement of their fingers on the map. PL4: 'I can remember a drawing or the movement of my fingers [touching the map].' Participants also developed tactile mental maps directly from their movements through paying attention to them and 'translating' the result to a mental representation. FR5: 'When I go somewhere I do not know I try to represent how you should turn, to make a small map ... in my head ... I have a tactile representation of my movements ... I can reduce them to a map like in geometry.' One participant was able to make three dimensional tactile representations. PL4: 'I remember everything in 3D ... If I need to I can create a tactile image in my head.' Inadvertent contact with obstacles with a cane could also be a useful source of information for tactile mental representations. For instance, PL12: [coding route details] 'often through sensory information ... e.g. there should be a bench there, as in the past I knocked it with my cane.'

Participants could then use their tactile memories of touching the plan to help them remember travel information. ES6: 'and what I have touched in the plan and its relationship with reality ... helps me retain a bit of the city in my head.' The value of mock-ups in supporting travel was also noted. ES6: 'a mock-up of the streets of the city is very useful ... it is complementary to walking along the street.'

Some participants were able to replay the mental (tactile) representation at increased speed. This was useful in reviewing routes. IT9: 'it is as if in my mind I redid this route faster ... it helps me when I need to do the route at normal speed as I remember that after this I need to do the other ... it is automatic.'

\subsubsection{Mental Maps from a Combination of Senses}

While, as discussed in the previous section, some participants had purely tctile mental maps, other used information from several different senses. Tactile and auditory landmarks remembered in sequence could be an important component of mental maps. IT3: 'I try to make a mental scheme of the route. ... mainly landmarks I use if I need to turn, landmarks on the ground ... mainly tactile ... auditory ... I remember them in sequence'. Some of the descriptions of developing auditory and tactile mental maps were very graphic and used the metaphor of time travel to present the process of using remembered tactile and auditory information to recreate routes mentally. IT10: 'Moving mentally ... is like travelling in time ... the others do it with their eyes and you do it with thought ... you create [the route] hearing who surrounds you. I hear and feel the type of street which enables me to get around.'

The use of smell was mentioned less frequently. However, odours were used together with other landmarks and participants noted the importance of combining information from different senses. IT17: 'When you travel as a blind person the 
smell of a bar, sounds, shops, how many roads you need to cross are all important. ... There are various landmarks and you need to learn them.' On unfamiliar routes smells could be used as landmarks to indicate, for instance, closeness to the destination. ES17: 'a friend ... invites me ... and I don't know the area, in advance I find out she has a rose bush... if I pass in front of a rose bush ... I say, it's there.'

Some participants retained sensory memories from all their senses and used them to support travel. IT9: 'I have the memory of the movements I make, I do not have an image in my mind ... I have a memory of the smells ... the sounds.' They were able to use these memories to form sensory pictures of their experiences along the route and to use these sensory pictures as landmarks. IT9: 'If I turn into a street where there is a bar with loud music and soon after I must turn left, I have a clear memory of this place and the people outside who are taking an aperitif ... I have the memory in my head of this place ... with these sounds, these smells, cafe in the morning and aperitif in the evening ... movement, sounds, smells ... together.'

\subsubsection{Retaining Audio Information as Data not Sensory Memories}

From the previous discussion in this section, many participants had direct sensory memories. However, some participants indicated that they had memories of tactile and/or visual information, but retained auditory data as information rather than sensory memories. An Italian participant discussed a range of tactile and other sensory memories of their route, but organised auditory information about the route as information. IT7: 'Memories are limited ... to the structure of the route, the sequence of bends, there are tactile memories of the ups and downs, memories of the slopes ... but hearing is used to imagine immediately available information, the volume of the traffic, the presence of cars,... a traffic light, but I do not use sound memories.'

A Spanish participant who used a combination of auditory and (quasi) visual data retained the auditory data as information rather than images or auditory memories. ES15: 'I do not convert the spoken information into images, I simply convert it into information to have the landmark to be able to get to the place. If they say: pass three roads in front and at the fourth turn to the right, you count: one, two, three and at the fourth you know you need to turn to the right, but you do not have it as visual information, no, it is auditory.' However, this participant retained visual memories of visual (or quasi visual) information. ES15: 'Putting as much images as possible [in my head] like the visual memory although it is limited ... you will always keep the image you caught on seeing a tree ... .' Another participant also combined visual images with information. PL16: '[I remember] routes, streets as an image, and the numbers of buses, trams as information.'

This raises the possibility of differences in the way information from the different senses is stored. In particular, there are questions of whether tactile and other sensory information is generally retained as sensory memory, but auditory data may be retained as information rather than a sensory memory, as well as the personal and situational factors that affect this.

\subsection{Moving Along the Route and Physical Sensations}




\subsubsection{Physical Memories and Representations of Moving Along the Route}

Several participants imagined themselves moving along the route. IT4. 'If I imagine it, it seems I am going on the route ... it seems like a flash back.' Body movements could form part of these memories. FR10: 'I also remember my body movements on the route ... the abstract memory is fed by the physical memory and when I think of the route ... I remember my body movements.'

Memories or mental maps of routes sometimes included various physical sensations experienced while travelling along them. This included imagining walking along and feeling the road surface and features such as turns. UK11: 'Just a series of roads and turns, and I imagine me walking along it .... Yes. I would imagine [feeling the road surface] ... because I'm imagining walking along it.' These memories could be experienced specifically in participants' legs. PL1: 'Naturally [I remember] in my legs ... I feel when there is a curb, stairs.' These physical sensations developed and became more detailed as participants learnt the route. IT20: 'I also manage to imagine myself physically as if moving and obviously the direction in which my body turns ... initially it is very schematic, like a line on a sheet ... later when I ... remember it well I can also project my body and movements into space.' This participant included loud sounds in their mental representation, but not smells and had a threedimensional memory/experience of their movements in space. IT20: 'smells no ... sounds if they are particularly loud. ... While describing this route ... I imagined it in 3D with my movements in space.'

A related mental representation involved the participant moving on the route as part of their mental map. IT1: 'Keeping the route in my mind is like having a mental map and the representation of myself moving on the route'. In some cases they imagined themselves moving along a map of the route rather than the route itself or imagined themselves from a height. IT7: 'I can imagine [the route] in different ways ... imagine myself inside the map when I go over the lines of the map, or I can imagine myself from a height as a point which I move as a line.'

Another approach involved remembering/modelling routes as a physical picture. UK16: 'It is an image but it is also physical layout of the area.' This physical picture could be quite detailed. UK8: 'physical picture ... not a visual one. ... Where I turn, where I went straight on. What the ground was like ... if there was anything significant like you know a sticking-out bush ... or a gap in the wall.' In some cases this physical picture included visual elements that the participant imagined. ES14: 'as I walk and go round ... the buildings ... I imagine ... the form, the perimeter of the shape of the buildings.... When I am walking along the street ... I imagine the people, the obstacles, I could meet, the doors ... like a photo ... When I am walking, not before.' Other participants experienced routes as a non-visual film. FR6: 'It is like a film being shown. You know what is happening there ... it takes place ... in my head.... I imagine it in my thoughts not visually.'

\subsubsection{Applications}

Mental maps based on physical memories could be used to support route learning and preview. Support for route learning could be obtained by participants trying to 
remember information about the route in their legs and not just their heads. For instance, PL1: 'What my guide told me ... I have it arranged in my head .... When I go somewhere I try to remember in my legs the first time.' The amount of time required for this 'physical' learning increased with the length of the route. PL1: 'If it is a short route, I can do this. If ... a few kilometres, ... I know it after the second, third time.' Another way physical memories of a route could be used to support route learning was by making movement along the route 'automatic' and thereby reducing cognitive effort. FR10: 'My body will make the movements ... so I do not need to think about it ... I have a memory of the route'. Participants were also able to use their physical sensations to develop their knowledge of route landmarks.

Physical memories also provided anticipation functions. This included knowing what was coming next. In some cases participants felt themselves automatically starting to move in a particular direction and this indicated what was coming next. UK16: 'I am walking along the road and I can physically know there is a left turning coming up. ... [your body starts to turn] ... Also, I am aware I need to go that way.'

\subsection{Images and Films}

\subsubsection{Types of Visual Representations}

Participants had a variety of different types of visual representations. One of the simplest options was the use of static schematic black and white line representations, which were sometimes in the form of a map. For instance, PL20: 'I need to create a map from my own understanding ... black and white, the streets are lines, the names of the streets ... it is very simple, schematic ... with black lines on a white background, I put the names next to the streets. I know how the street runs, which are the intersecting streets. ... The scheme is in my head.' This type of schematic representation could be one or two dimensional. The following is a twodimensional example IT7: 'I imagine it ... with white background and black lines ... it is two dimensional like a map.'

There were also dynamic schematic representations. The following one-dimensional example is probably dynamic rather than static, as it involves the participant using line drawings in their mind to represent their movements along the route. IT20: 'I make a sort of mental model ... a sort of drawing in my mind ... if I need to go straight I imagine a straight line, if I need to go round a bend I imagine the bend ... If I need to cross ... I imagine another line which makes me cross the street. It is a model made up of lines. ... It is a bit like a visual image. ... It is like a line on a sheet of paper, not two or three - dimensional.'

Participants also had realistic representations. These included images in colour. FR12: 'I have constructed a plan in my head ... a bit like an image in my head ... in colour.' Other examples of realistic representations were similar to a photo. PL2: 'I start thinking of a road in my village ... and I think of the traffic lights and then of the roads, the trees round there, they appear immediately like a photo ... when the image appears, it shows everything, at the sides, the front, all the road.' 
The details of participants' representations were of varying clarity, depending on the extent of their prior knowledge of the objects represented. UK3: 'I would visualise that there are buildings of a sort and if I had used the shops ... I would visualise them as shops. ... if I saw houses and I hadn't used them, I would just know that they were buildings. I wouldn't necessarily know what they were used for.' Some participants formed global visual representations. FR14: 'All my representations are visual ... to know a place I remember ... it is generally a bit global, information that could be useful.'

Analogously to some participants having a physical memory of their movements along the route (see section 3.4), others saw themselves moving along the route. UK19: 'I have a picture or an image ... of the route. ... And it's almost as if I were doing the same route, but without me being able to see the picture in front of me all the time.' A related approach was a mental film. FR15: 'I make films in my head.' A futher variation involved participants mentally seeing themselves moving along the route. UK3: 'I have a sort of a map in my mind of the particular route ... If I' $m$ thinking about walking a route, obviously l'm seeing in my mind coming out of the house, and I'm seeing turning left, ... it's a visual thing.'

\subsubsection{Forming Visual Representations}

In addition to the approaches to forming visual mental representations implied in the previous section, some participants were also to derive them from descriptions and others used mental drawing. The following is an example of obtaining a mental representation from a description. FR12: 'I have visual representations. When someone describes a landscape to me I make a mental image.' Mentally drawing routes they had seen could include features such as turns and bends. IT3: 'as I have seen it in the past, I could also draw the route ... and this is something that I do, if I have gone straight or round a bend, then turn right ... and therefore I am able to reconstruct it in my mind.'

\subsubsection{Memories and the Reality of Visual Information}

Since several of the participants had become blind after having had some vision in the past, many of their visual representations were based on remembered information. This stored information could be used to help them imagine the route. PL7: 'As a blind person I need to imagine the route ... I have stored a view of the real world. There are fragments of the routes which I used previously.' In some cases these memories were particularly vivid. PL7: 'Sometimes it is as if my eyes are seeing something from the times I could see.' However, participants who became blind in childhood had more limited memories, based on what they had paid attention to then. ES18: 'I have retained ... the image of a table ... a meadow ... a beach ... as these things make an impression on a six year old child and are retained in their mind. I do not have ... images of streets ... I have a very long straight line which would be the street and ... between the second and third road I will come to ... a garden, but I do not have an image of the garden.'

Possibly because they were frequently based on remembered information, participants were diffident about the extent to which their representations were indeed visual. For instance, FR10: 'I make a mental representation which is a bit 
visual and a bit not visual.' This questioning also extended to the accuracy of their visual representations. UK19: 'I sort of have a visual picture in my mind of anything I do, whether it's accurate, I don't know'.

\subsubsection{Applications}

Participants with visual representations were able to use them to support travel in several different ways. For instance, visual memories could be used to help participants interpret what they encountered while travelling. UK10: 'Often visual. When you have seen you make a plan. It helps a lot. ... when I go past a road I knew a bit what it is like. I know I am passing in front of particular things.'

Another way in which they used visual representations was to use mental drawing to support route planning and to work out return routes. PL16: 'While I walk I try to draw in my head a plan of the way back. Sometimes I do not return by the same route, as another is ... e.g. shorter ... If someone tells me how and with what transport to go and I have the full address ... I can work out the route in my head and get there, unless it is difficult to access, outside the city, there is no-one to ask.' Mental drawing could also be used on public transport, for instance to work our the location while travelling by bus. IT7: 'I draw a map in my mind ... it is useful for travelling bus routes you know and following the turns of the bus you know quite accurately where you are.'

Global visual representations could enable participants to relate different places to important locations, such as home or work. FR12: 'I have a global representation of places I know well. ... I place the buildings with respect to where I work.'

\section{Discussion and Conclusions}

The paper has used data from 100 blind people in five different countries to discuss the following three questions:

1. How do blind people represent space and what sensory modalities do they use to do this?

2. How do blind people use their spatial representations to support travel?

3. What are the implications of the responses for the design of travel aids and orientation and mobility training?

Participants were chosen to have diverse characteristics, though the aim was to obtain rich data rather than a statistically representative sample. To increase the likelihood of including participants with experience of route learning and who did not mainly use sight in spatial exploration the participants chosen from the larger sample all experienced significant mobility barriers and had experience of unaccompanied travel.

The literature has considered the spatial abilities of early and late blind people, particularly in comparison to those of sighted people and the nature and role of mental maps, particularly as used by sighted people. However, there seems to have been minimal if any discussion of mental map use by blind and partially sighted people, including whether they have mental maps and, if so, the sensory modalities 
used, how they are developed and their role in supporting travel. In addition, very limited attention has been given to the perspective of blind and partially sighted people.

This work has made a significant contribution to filling these gaps by (i) discussing the spatial representations used by blind and partially sighted people; (ii) discussing experiences of mental maps use while travelling rather than engaged in experiments; (iii) drawing on the perspective of blind and partially sighted people through interview data.

\subsection{The Representation of Space}

The results show that most participants (54) represented space through the development of a mental representation or mental map. As in the case of sighted people [Tversky, 2003] mental maps were frequently simplified and schematic, used squares and straight lines and found parallel routes easier to represent than diagonals, in line with the literature on the importance of grids in mental maps [Kuipers, 1978]. However, participants also used abstract representations.

One of the participants had a store of mental representations which contained a variety of useful details, including 'poles, kerbs, road works.' Several other participants indicated the importance to them of road works. This extends the literature on mental maps possibly including object locations and fixed features [Kaplan, 1976; Kuipers, 1983] to indicate that for at least some blind people they may possibly also include temporary features, such as road works. However, further research will be required to investigate this in detail. The literature is inconclusive about the use of mental stores [Loader, 2013]. However, as the participant's comments indicate, there would probably be benefits in encouraging blind people to try to develop stores of mental maps.

Many (17), of the participants had global representations. Some of them started from a global perspective, for instance developing a structured framework, and added details, whereas others started from a local perspective and added additional information as they learnt it. Many participants had very detailed representations, in line with the literature on blind people using more information and landmarks and having more complex and detailed route descriptions than sighted people [Harper and Green, 2007; Passini and Proulx, 1988], the view was also expressed that too much detail could lead to cognitive overload. Although none of the participants states this explicitly, there are indications that good mental maps could be used to manage and reduce cognitive load.

Several participants had developed representations of different parts of a city, but had had varying degrees of success in relating them to each other. Many participants were only interested in the information they required for their particular routes, in line with the need to manage cognitive effort due to the greater cognitive effort they already required to travel [Fortin et al., 2008]. Consequently, they minimised attention to additional information, for instance associated with survey representations. However, there is at least anecdotal evidence that sighted people also tend to focus on relevant (travel) information and ignore details not relevant to 
their particular journey. While supporting the existing literature on blind people's preferences for route over survey representations [Thinus-Blanc and Gaunet 1997], the paper moves beyond it in giving a rationale for this preference. From their comments, it seems that French participants may have had a greater interest in combining the mental maps of different areas of a city and Polish participants focussed largely on routes of areas of interest. However, further research would be required to determine the extent of the difference between French and Polish participants in this respect and investigate the reasons for it. In addition, it should be noted that, while expressing a preference for focussing on relevant areas to reduce unnecessary effort, one of the Polish participants stated that they were able to combine some areas and relate them to the whole. In addition, French participants seemed to have the greatest interest in global representations, followed by Italian participants. However, further research would again be required to verify this and investigate the reasons for it.

Participants' responses showed that they used various combinations of their senses to obtain travel information. In line with the literature on the importance of both audio and tactile travel information to blind people [Kulyukin et al., 2008] and landmarks [Millonig and Schechtner, 2007; Raubal and Winter, 2002], tactile and auditory landmarks were frequently an important component of mental maps and mentioned more often than other types of sensory information. Several participants had a mixture of tactile, auditory and olfactory sensory memories. However, others had sensory memories of tactile information and smells, but remembered speech in the form of information. There is a need for further research to investigate the frequency of the storage of audio data as information and the factors that affect this.

Participants had obtained tactile representations both from walking routes and touching tactile maps, following the literature on the usefulness of tactile maps in supporting route learning [Jacobson, 1998] and audio tactile maps in the accuracy and detail of cognitive maps [Jacobson, 1998; Koukourikos and Papadopoulos, 2015].

Several participants experienced physical sensations or memories of moving along the route. In some cases these sensations were schematic and became more detailed with time. There are some parallels in the literature on movement being one of the important sources of information in the formation of spatial representations [Waller and Greenauer, 2007]. There is also some relationship to the literature on the importance of embodiment and the role of the body and awareness of it in various activities e.g. [Edensor, 2000; Hockey and Collinson 2007]. However, this type of physical memory and the role of physical sensations in route learning seem not to have been discussed previously.

Some participants were able to replay their representations at increased speed and/or vary the speed at which they imagined themselves walking along the route in order to focus on particular aspects of it. This indicates that at least some blind people have a proportional relationship between distance and time in line with Afonso's [2010] work which indicates that blind people have metric representations.

Participants with visual experience had visual representations, which were often schematic and lacked colour. In some cases these representations involved them moving along the route, analogously to participants feeling themselves moving 
physically along the route. They were frequently based on memories due to no longer having access to visual information after the onset of blindness.

Consequently, the visual elements for people who had become blind in childhood were limited to what they were familiar with as children.

The presentation of the results in section 3 and the above discussion make it clear that the spatial representations of blind and partially sighted people are very diverse. It is therefore useful to draw up a classification which includes the main factors. However, further research will be required to develop if further and relate the different types of representations to personal characteristics and contextual and other factors. A preliminary two-stage classification model is presented below.

I Sensory information

- (Combination of) types of sensory information

- Presentation e.g. as sensory memories or information

II Representation

- Schematic or realistic

- Stationary or dynamic, including the person moving along the route

- Perspective, including in, above, at the side of the mental map

- Global or local.

\subsection{The Use of Spatial Representations to Support Travel}

Many participants used their mental maps to support effective travel and prevent getting lost, in line with the literature [Siegel and White, 1975]. Mental maps could be used to organise information and support previewing landmarks and avoiding potential problems. While the organisational role of mental maps is also relevant to sighted people, the preview role is specific to blind people. The need for it results from the different types of information provided by the different senses [Pissaloux et al., 2016] and the lack of broad band distant preview information from the senses other than vision. Thus, the preview role enables blind people to determine whether they are on the right route by checking for the presence of expected landmarks and gives advance warning of known difficulties to allow effective action. For participants who required a large number of landmarks a mental map could support organising them. Participants' comments also indicated that having a mental map increased their confidence as travellers.

In addition, a mental map provided blind (and sighted) people with a context for travel information. Having a structure in which to store route information enabled them to determine the appropriate route for a particular journey, including the bus number. Having a mental map reduced the likelihood of getting lost and made it easier to get to subsequent destinations, in line with the literature on mental maps being adopted to support travel and the implementation of travel plans [Gärling et al., 1984].

A mental map can also provide a supporting context for asking other people for information. For instance, it can allow a blind person to ask how to get to a relatively well-known landmark which is close to their destination rather than asking for a 
possibly little-known small shop or side road. It can also help people make sense of the responses. There has been little discussion of these roles for cognitive maps in the literature.

\subsection{The Implications for Developing Travel Aids}

This paper has increased understanding of how blind and partially sighted people represent space using mental maps and how they use these representations to support travel. It has shown that many blind people have very well-developed spatial understanding and spatial representations. These take various formats and further work will be required to determine a taxonomy of how different factors impact on the type of representation used.

This understanding can be very useful in supporting both orientation and mobility training and the design of travel aids. Understanding of the different strategies used to form mental maps and use them to support travel could add to the repertoire of orientation and mobility instructors in training blind and partially sighted people to understand space and improve their exploration and learning strategies.

Travel aids can be considered information processing devices which obtain information from the environment and convey it in an appropriate format to the user. More recently, travel aids have also obtained information from other sources, such as databases and the internet. As discussed in section 1.3, development of electronic travel aids can be divided into three overlapping phases, with developments in the first two phases still continuing. The first phase involves obstacle detection/avoidance devices with additional functionality, typically related to providing information about obstacles at a greater distance and/or height than the long cane. Many of these devices are either attached to a traditional long cane or have the form of a long cane with integrated components to provide additional functionality e.g. the laser cane, the smart cane, the ultracane, the Tom Pouce and Télétact [Pissaloux et al., 2016], the EyeCane [Buchs et al, 2017] and electronic long cane [Hersh and García Ramírez, 2018]. Others involve an attachment to spectacles or other headworn devices e.g. iSonar [Vorapatratorn and Nambunmee, 2014] and iSonar2 [Vorapatratorn and Teachavorasinskun, 2017].

There is also increasing interest in (RGB-D) cameras with signal processing algorithms to obtain and extract environmental information e.g [Arditi and Tyan, 2013; Kumar et al., 2011; Lee and Medioni, 2016; Li et al, 2015]. Such devices are able to provide additional and more detailed information than other devices. This information could be used to give greater understanding of the surrounding environment and develop a mental map of it.

One of the continuing challenges is the best way to present the additional information to facilitate its mental processing and comprehension and prompt an appropriate reaction or support development of a mental map, while avoiding cognitive overload and interference with access to environmental sounds. Understanding of the underlying structures of blind people's spatial representations or mental maps could be very useful here, as mental maps provide a framework in which to integrate and comprehend information. The additional information should 
be provided in a way that is compatible with and easily integrated into existing mental maps and can facilitate the building of new ones if needed. This may require information to be provided in different formats for different groups of users.

While as indicated above, there are still unsolved problems in the area of obstacle avoidance, some of the work in this area seems to be technology rather than enduser driven. In the relatively limited cases where authors indicate that end-users were involved in the development, details are not always provided. Based on the evidence to date it seems unlikely that usage of electronic canes and other phase one devices will ever approach that of the long cane, which is still the most frequently used mobility device [Hersh, 2015]. While these devices can still have an important role on a smaller scale, many researchers and developers require greater clarity as to the intended aims and role of the devices they are developing. A model with some degree of success in the area of electronic canes is the production of a small number of devices, with the developer organising a training programme and/or remaining in contact with and continuing to provide support for users. Examples include the Tom Pouce and Télétact [Pissaloux et al., 2016] and the electronic long cane [Hersh and García Ramírez, 2018].

The second phase involves navigation and wayfinding devices using global navigation satellite systems and environmental information beacons with RFID tags or IR transmitters [Farcy et al., 2006]. The outstanding challenges include developing systems which can be used in navigation both inside and outside, systems which work for the last 10 metres or so over which GPS is inaccurate and the additional information and functions associated with environmental information beacons. Understanding of mental maps could inform decisions on additional information to be provided by environmental information beacons. Awareness of the types of information blind people include in their mental maps could inform the development of additional information categories in GPS points of interest and the choice of additional GPS functions.

There is an increasing focus on indoor navigation and location, but as yet little attention has been given to the design of navigation and location devices which can be used both inside and outside. While environmental information beacons can be used indoors, GPS cannot, thereby complicating the problem of indoor navigation. In the context of indoor navigation the useful distinction has been made between building dependent and building independent technologies [Alarifi et al., 2016]. The authors provides a useful overview of the advantages and disadvantages of the two approaches. However, they did not mention the important disadvantage of the building dependent approach only working in buildings with existing technology, such as tagged facilities and features, or where a map and structural knowledge are available. Drawing on knowledge of the spatial representations of blind people could again facilitate the development of more effective technologies for in-building location and navigation, as well as devices which can be used both inside and outside.

Other interesting approaches include the use of free floating quadcopters [Soto and Funk, 2018] and the provision of all-round environmental information by vibro-tactile rhythms on a waist wrap. However, significant problems still need to be resolved. In the quadrocopter case rotor noise is both irritating and could interfere with important 
environmental sound information. In the waist wrap case the vibration could cause irritation and/or nausea to some users. This illustrates the importance of greater understanding of end-user needs and the potential problems associated with particular design choices, so they can be taken into account in device design. A navigation system using particle fusion on a mobile device [Rituerdo et al., 2016] has potential, but the need to wear a smartphone on a lanyard could be a disadvantage, as this is not the standard way smartphones are used.

The third phase involves the development of apps on smart mobile devices and vision sensors linked to smart mobile devices e.g. Find my bus/stop and context aware systems [Gharani and Karimi, 2017]. Outstanding challenges include the use of these approaches in wide ranging multifunction navigation, obstacle avoidance and information systems. Understanding of blind people's mental maps will enable them to be used as a framework in which to interpret information. This will support choices of the types of information to best complement existing mental models and their provision in ways that are compatible with and can be most easily integrated with existing mental maps.

Apps have a number of advantages and provide a variety of potentially interesting opportunities. These include relatively low development costs and the relevance to the general population of some apps of interest to blind people. The wide usage of apps on mobile devices means that there is no stigma associated with their use. This is important, as concerns about stigma have been found to have a negative impact on the use of the long cane and other assistive devices [Hersh, 2013a, 2015]. A further advantage is the likelihood of use of an existing device to reduce both costs and learning time. However, some applications will probably require additional hardware. A particular case is that of obstacle avoidance devices and the provision of sufficient information on the positions of obstacles to enable blind people to safely avoid them without the need for additional hardware. This is likely to depend on the person's mobility skills and to be facilitated by an understanding of how blind people form mental maps. The latter will enable devices to provide information in a form which is easier to understand and use effectively.

There is also some potential in the use of virtual reality and other technologies which can support the development of spatial knowledge of an environment e.g. [Alarifi et al, 2016; Ghali et al., 2012]. However, there has been minimal, if any, consideration the different types of spatial representations used by blind people and how this knowledge could be used to facilitate access to environmental information.

One of the issues raised by participants in section 3.1.2 and relevant to the development of many types of travel aids is the use of mental maps to provide preview and anticipation functions. Phase 1 devices aim to do this over a greater distance and/or height than the long cane and phase 2 and 3 devices have the potential to provide greater preview and anticipation. Understanding of the mental maps of blind people could be used to develop devices with more effective preview and anticipation functions which take account of how they use mental maps and integrate these functions with the existing mental map framework.

Despite the potentially very great importance of understanding the spatial perceptions and representations of blind people, little attention has been given to this 
in travel aid development. The few exceptions include [Guerreiro et al., 2017], though their approach is limited to consideration of blind people's ability to construct sequential environmental representations.

In summary, there is considerable active research in the area of travel aids and some of the developments, particularly on the use of apps, could be very useful. However, some of the work seems to be technology rather than end-user driven. The motivation frequently seems the potential of particular technologies rather than awareness of the continuing barriers experienced by blind people to effective travel and potential solutions to overcome these barriers. Thus further development should be much more clearly rooted in understanding and meeting blind people's needs. As discussed in this section, understanding of mental models has an important role in ensuring that travel aid developments are better targeted to do this.

\subsection{Further Research}

Further research is still required in a number of different areas, including the following:

1. Classification model: This should include further development and validation of the model presented in section 4.1. It should also include any restrictions on its validity or modifications to take account

2. Factors which affect mental maps: This will involve an investigation of whether and, if so, how different factors affect the mental maps used by blind people. The factors that can usefully be investigated include, but are not limited to, the type of urban design, the type of orientation and mobility training (or its lack), type and history of development of visual impairment, national and cultural factors, as well as demographic factors such as age and gender. This investigation should also consider any interactions between the different factors in their effects on mental maps.

3. Mental map effectiveness: A particularly important factor to be investigated is the impact of mental map use on successful travel behaviour. This should include investigation of whether and, if so, how the type of mental map used affects travel behaviour and what types of travel behaviour are successful and in which circumstances. Consideration should also be given to the impacts of personal and situational factors on the effectiveness of mental maps in supporting successful travel. It may be helpful to derive metrics to define successful travel behaviour.

4. Representations based on sensory memories and information: This would involve an investigation of the factors that determine whether sensory information is stored as sensory memories or information. This should include consideration of whether audio information is more likely that other sensory information to be stored as information rather than sensory memories. A further area for investigation is whether blind (and some partially sighted) people retain tactile and auditory memories to a greater extent than sighted people.

\section{ACKNOWLEDGEMENT}

I would like to thank the Leverhulme Trust for the award of a Research Fellowship which supported this work and the many blind, partially sighted and deafblind people 
who gave of their time and expertise and the colleagues and organisations who provided me with support. To single out a few of them, particular thanks are due to Hanna Pasterny and CRIS, Monica Schmid and l'Instituto Maugeri, Mario Barbuto and l'Instituto Cavazza, la Fédération des Associations des Chiens Guides, René Farcy, ONCE in Santander and La Rioja and Polski Związek Niewidomych. I would also like to thank Frank Pollick and Mike Johnson and the anonymous reviewers for their very helpful suggestions and comments.

\section{References}

1. Afonso, A., Blum, A., Katz, B. F., Tarroux, P., Borst, G., \& Denis, M. (2010). Structural properties of spatial representations in blind people: Scanning images constructed from haptic exploration or from locomotion in a 3-D audio virtual environment. Memory \& cognition, 38(5), 591-604.

2. Alarifi, A., Al-Salman, A., Alsaleh, M., Alnafessah, A., Al-Hadhrami, S., AlAmmar, M. A., \& Al-Khalifa, H. S. (2016). Ultra wideband indoor positioning technologies: Analysis and recent advances. Sensors, 16(5), 707.

3. Arditi, A., \& Tian, Y. (2013). User interface preferences in the design of a camera-based navigation and wayfinding aid. Journal of Visual Impairment \& Blindness, 107(2), 18-129.

4. Bai, J., Liu, Z., Lin, Y., Li, Y., Lian, S., \& Liu, D. (2019). Wearable Travel Aid for Environment Perception and Navigation of Visually Impaired People. Electronics, 8(6), 697.

5. Boeije, H. (2010). Analysis in qualitative research. London, England: Sage Publications Ltd.

6. Briggs, R. (1973). Urban distance cognition, In R.M. Downs and D. Stea (eds). Image and Environment, Aldine, pp. 361-388.

7. Bryant, D. J. (1997). Representing space in language and perception. Mind \& Language, 12(3 - 4), 239-264.

8. Buchs, G., Simon, N., Maidenbaum, S., \& Amedi, A. (2017). Waist-up protection for blind individuals using the EyeCane as a primary and secondary mobility aid. Restorative neurology and neuroscience, 35(2), 225-235.

9. Byrne, R.W. and E. Salter (1983). Distances and directions in the cognitive maps of the blind, Canadian J. Psychology, vol. 37(2), pp. 293-399.

10. Corazzini, L., Tinti, C., Schmidt, S., Mirandola, C., \& Cornoldi, C. (2010). Developing spatial knowledge in the absence of vision: allocentric and egocentric representations generated by blind people when supported by auditory cues. Psychologica Belgica, 50(3-4).

11. Cronly-Dillon, J., Persaud, K. C., \& Blore, R. (2000). Blind subjects construct conscious mental images of visual scenes encoded in musical form. Proceedings of the Royal Society of London B: Biological Sciences, 267(1458), 2231-2238.

12. deFatima, M., Almedia, X.M., Martins, L. B., \& Lima, F. J. (2015). Analysis of wayfinding strategies of blind people using tactile maps. Procedia Manufacturing, 3, 6020-6027.

13. Downs, R. M., \& Stea, D. (1977). Maps in minds: Reflections on cognitive mapping. HarperCollins Publishers.

14. Edensor, T. (2000). Walking in the British countryside: reflexivity, embodied practices and ways to escape. Body \& Society, 6(3-4), 81-106. 
15. Espinosa, M. A., Ungar, S., Ochaíta, E., Blades, M., \& Spencer, C. (1998). Comparing methods for introducing blind and visually impaired people to unfamiliar urban environments. Journal of Environmental Psychology, 18(3), 277-287.

16. Farcy, R., Leroux, R., Jucha, A., Damaschini, R., Grégoire, C., \& Zogaghi, A. (2006, July). Electronic travel aids and electronic orientation aids for blind people: Technical, rehabilitation and everyday life points of view. In Conference \& Workshop on Assistive Technologies for People with Vision \& Hearing Impairments Technology for Inclusion (Vol. 12).

17. Fernandes, H., Costa, P., Filipe, V., Paredes, H., \& Barroso, J. (2019). A review of assistive spatial orientation and navigation technologies for the visually impaired. Universal Access in the Information Society, 18(1), 155-168.

18. Fortin, M., Voss, P., Lord, C., Lassonde, M., Pruessner, J., Saint-Amour, D., ... \& Lepore, F. (2008). Wayfinding in the blind: larger hippocampal volume and supranormal spatial navigation. Brain, 131(11), 2995-3005.

19. Gärling, T., Book, A., \& Lindberg, E. (1984). Cognitive mapping of large-scale environments: The interrelationship of action plans, acquisition, and orientation. Environment and behavior, 16(1), 3-34.

20. Ghali, N. I., Soluiman, O., El-Bendary, N., Nassef, T. M., Ahmed, S. A., Elbarawy, Y. M., \& Hassanien, A. E. (2012). Virtual reality technology for blind and visual impaired people: reviews and recent advances. In Advances in Robotics and Virtual Reality (pp. 363-385). Springer, Berlin, Heidelberg.

21. Gharani, P., \& Karimi, H. A. (2017). Context-aware obstacle detection for navigation by visually impaired. Image and Vision Computing, 64, 103-115.

22. Ghilardi, M. C., Macedo, R. C., \& Manssour, I. H. (2016). A new approach for automatic detection of tactile paving surfaces in sidewalks. Procedia computer science, 80, 662-672.

23. Giudice, N. A., Betty, M. R., \& Loomis, J. M. (2011). Functional equivalence of spatial images from touch and vision: Evidence from spatial updating in blind and sighted individuals. Journal of Experimental Psychology: Learning, Memory, and Cognition, 37(3), 621.

24. Giudice, N. A., Klatzky, R. L., \& Loomis, J. M. (2009). Evidence for amodal representations after bimodal learning: Integration of haptic-visual layouts into a common spatial image. Spatial Cognition \& Computation, 9(4), 287-304.

25. González-Mora, J. L., Rodriguez-Hernandez, A., Rodriguez-Ramos, L. F., DíazSaco, L., \& Sosa, N. (1999, June). Development of a new space perception system for blind people, based on the creation of a virtual acoustic space. In International Work-Conference on Artificial Neural Networks (pp. 321-330). Springer, Berlin, Heidelberg.

26. Guerreiro, J., Ahmetovic, D., Kitani, K. M., \& Asakawa, C. (2017, October). Virtual navigation for blind people: Building sequential representations of the real-world. In Proceedings of the 19th International ACM SIGACCESS Conference on Computers and Accessibility (pp. 280-289). ACM.

27. Halko, M. A., Connors, E. C., Sánchez, J., \& Merabet, L. B. (2014). Real world navigation independence in the early blind correlates with differential brain activity associated with virtual navigation. Human brain mapping, 35(6), 27682778.

28. Harper, S., \& Green, P. (2000). A travel flow and mobility framework for visually impaired travellers. In International Conference on Computers Helping People with Special Needs (pp. 289-296). 
29. Held, R. and J. Rekosh (1963). Motor-sensory feedback and the geometry of visual space, Science, vol. 141, pp. 722-723.

30. Hersh, M.A. (2009a). The application of information and other technologies to improve the mobility of blind, visually impaired and deafblind people, in Travel Health Informatics and Telehealth, Selected Papers from EFMI Special Topic Conference, Antalya, Turkey, G. Mihalaş et. al. (eds.) pp. 11-24, Victor Babes University Publishing House.

31. Hersh, M.A. (2009b). Designing assistive technology to support independent travel for blind and visually impaired people. CVHI '09, Wrocław.

32. Hersh MA. (2010). Methodological issues in multi-country multi-language participative research with blind and visually impaired people, SWIIS '10, Pristina, Kosovo.

33. Hersh MA. (2011). Participative research with diverse end-user groups: multilanguage, multi-country blind and visually impaired people, $18^{\text {th }}$ IFAC Congress, Milan, Italy.

34. Hersh, M. A. (2013a). Deafblind people, stigma and the use of communication and mobility assistive devices. Technology and Disability, 25(4), 245-261.

35. Hersh, M. (2013b). Deafblind people, communication, independence, and isolation. Journal of deaf studies and deaf education, 18(4), 446-463.

36. Hersh, M. (2015). Cane use and late onset visual impairment. Technology and Disability, 27(3), 103-116.

37. Hersh, M. A. (2016). Improving deafblind travelers' experiences: an international survey. Journal of Travel Research, 55(3), 380-394.

38. Hersh, M. A., \& García Ramírez, A. R. (2018). Evaluation of the electronic long cane: improving mobility in urban environments. Behaviour \& Information Technology, 37(12), 1203-1223.

39. Hockey, J., \& Collinson, J. A. (2007). Grasping the phenomenology of sporting bodies. International review for the sociology of sport, 42(2), 115-131.

40. Ivanov, R. (2017). An approach for developing indoor navigation systems for visually impaired people using Building Information Modeling. Journal of Ambient Intelligence and Smart Environments, 9(4), 449-467.

41. Jacobson, R. D. (1998). Cognitive mapping without sight: Four preliminary studies of spatial learning. Journal of Environmental Psychology, 18(3), 289-305.

42. Kaplan, S. (1973). Cognitive maps in perception and thought, In R.M. Downs and D. Stea (eds). Image and Environment, Aldine, pp. 63-78.

43. Kaplan, S. (1976). Adaptation, structure and knowledge, In G.T. Moore and R.G. Golledge (eds.) Environmental Knowing, Hutchinson and Ross, pp. 32-45.

44. Kayukawa, S., Higuchi, K., Guerreiro, J., Morishima, S., Sato, Y., Kitani, K., \& Asakawa, C. (2019, April). BBeep: A Sonic Collision Avoidance System for Blind Travellers and Nearby Pedestrians. In Proceedings of the $2019 \mathrm{CHI}$ Conference on Human Factors in Computing Systems (p. 52).

45. Kitchin, R. M. (1994). Cognitive maps: What are they and why study them?. Journal of environmental psychology, 14(1), 1-19.

46. Koukourikos, P., \& Papadopoulos, K. (2015). Development of cognitive maps by individuals with Blindness using a multisensory application. Procedia Computer Science, 67, 213-222.

47. Kuipers, B. (1978). Modeling spatial knowledge. Cognitive science, 2(2), 129153.

48. Kuipers, B. (1983). The cognitive map: Could it have been any other way?. In Spatial orientation (pp. 345-359). Springer, Boston, MA. 
49. Kulyukin, V. A., Nicholson, J., Ross, D. A., Marston, J. R., \& Gaunet, F. (2008, March). The Blind Leading the Blind: Toward Collaborative Online Route Information Management by Individuals with Visual Impairments. In AAAI Spring Symposium: Social Information Processing (pp. 54-59).

50. Kumar, A., Patra, R., Manjunatha, M., Mukhopadhyay, J., \& Majumdar, A. K. (2011, January). An electronic travel aid for navigation of visually impaired persons. In Communication Systems and Networks (COMSNETS), 2011 Third International Conference on (pp. 1-5).

51. Lee, Y. H., \& Medioni, G. (2016). RGB-D camera based wearable navigation system for the visually impaired. Computer Vision and Image Understanding, 149, 3-20.

52. Lehnert, G., \& Zimmer, H. D. (2008). Common coding of auditory and visual spatial information in working memory. Brain research, 1230, 158-167.

53. Lerens, E., \& Renier, L. (2014). Does visual experience influence the spatial distribution of auditory attention?. Acta psychologica, 146, 58-62.

54. Li, B., Munoz, J. P., Rong, X., Xiao, J., Tian, Y., \& Arditi, A. (2016, October). ISANA: wearable context-aware indoor assistive navigation with obstacle avoidance for the blind. In European Conference on Computer Vision (pp. 448462). Springer, Cham.

55. Li, B., Muñoz, J. P., Rong, X., Chen, Q., Xiao, J., Tian, Y., ... \& Yousuf, M. (2019). Vision-based mobile indoor assistive navigation aid for blind people. IEEE transactions on mobile computing, 18(3), 702-714.

56. Li, B., Zhang, X., Muñoz, J. P., Xiao, J., Rong, X., \& Tian, Y. (2015, December). Assisting blind people to avoid obstacles: An wearable obstacle stereo feedback system based on 3D detection. In 2015 IEEE International Conference on Robotics and Biomimetics (ROBIO) (pp. 2307-2311). IEEE.

57. Loader, P. (2013). Is my memory an extended notebook?. Review of Philosophy and Psychology, 4(1), 167-184.

58. Loomis, J. M., Klatzky, R. L., McHugh, B., \& Giudice, N. A. (2012). Spatial working memory for locations specified by vision and audition: Testing the amodality hypothesis. Attention, Perception, \& Psychophysics, 74(6), 12601267.

59. Lynch, K. (1960). The Image of the City, MIT Press, Cambridge, Mass.

60. Millar, S. (1988). Models of sensory deprivation: The nature/nurture dichotomy and spatial representation in the blind. International Journal of Behavioral Development, 11(1), 69-87.

61. Millonig, A., \& Schechtner, K. (2007). Developing landmark-based pedestriannavigation systems. IEEE Transactions on intelligent transportation systems, 8(1), 43-49.

62. Newell, F. N., Woods, A. T., Mernagh, M., \& Bülthoff, H. H. (2005). Visual, haptic and crossmodal recognition of scenes. Experimental Brain Research, 161(2), 233-242.

63. Noordzij, M. L., Zuidhoek, S., \& Postma, A. (2006). The influence of visual experience on the ability to form spatial mental models based on route and survey descriptions. Cognition, 100(2), 321-342.

64. Ohuchi, M., Iwaya, Y., \& Suzuki, Y. (2006). Cognitive-map forming of the blind in virtual sound environment. Georgia Institute of Technology.

65. Passini, R., \& Proulx, G. (1988). Wayfinding without vision: An experiment with congenitally totally blind people. Environment and Behavior, 20(2), 227-252. 
66. Periasamy, C., \& Krishnapriya, V. (2019). Electronic Travel Aid for Visually Impaired People Along with a Panic Alert System. International Journal of Computer Communication and Informatics, 1(1), 17-21.

67. Péruch, P., Gaunet, F., Thinus-Blanc, C., \& Loomis, J. (2000). Understanding and learning virtual spaces. Cognitive mapping: Past, present and future, 4.

68. Pissaloux, E., Velazquez, R. Hersh, M and Uzan, G. (2016). Towards a cognitive model of human mobility: an investigation of tactile perception for use in mobility devices. Journal of Navigation vol. 70, no. 1, pp 1-17.

69. Raubal, M., \& Winter, S. (2002, September). Enriching wayfinding instructions with local landmarks. In International conference on geographic information science (pp. 243-259). Springer, Berlin, Heidelberg.

70. Rieser, J. J., Guth, D. A., \& Hill, E. W. (1986). Sensitivity to perspective structure while walking without vision. Perception, 15(2), 173-188.

71. Rituerto, A., Fusco, G., \& Coughlan, J. M. (2016, October). Towards a signbased indoor navigation system for people with visual impairments. In Proceedings of the 18th International ACM SIGACCESS Conference on Computers and Accessibility (pp. 287-288). ACM.

72. Schmidt, S., Tinti, C., Fantino, M., Mammarella, I. C., \& Cornoldi, C. (2013). Spatial representations in blind people: The role of strategies and mobility skills. Acta Psychologica, 142(1), 43-50.

73. Siegel, A. W., \& White, S. H. (1975). The development of spatial representations of large-scale environments. In Advances in child development and behavior (Vol. 10, pp. 9-55). JAI.

74. Soto, M. A., \& Funk, M. (2018). Look, a guidance drone! Assessing the Social Acceptability of Companion Drones for Blind Travelers in Public Spaces. In Proceedings of the 20th International ACM SIGACCESS Conference on Computers and Accessibility. ACM, New York, NY, USA (pp. 417-419).

75. Spencer, C., Blades, M., \& Morsley, K. (1989). The child in the physical environment: The development of spatial knowledge and cognition. John Wiley \& Sons.

76. Thinus-Blanc, C. and F. Gaunet (1997). Representation of space in blind persons: vision as a spatial sense?, Psychological Bulletin, 121(1), 20-42.

77. Tinti, C., Adenzato, M., Tamietto, M., \& Cornoldi, C. (2006). Visual experience is not necessary for efficient survey spatial cognition: evidence from blindness. The Quarterly Journal of Experimental Psychology, 59(7), 1306-1328.

78. Tolman, E. C. (1948). Cognitive maps in rats and men. Psychological review, 55(4), 189.

79. Tversky, B. (1993). Cognitive maps, cognitive collages, and spatial mental models. In European conference on spatial information theory (pp. 14-24). Springer, Berlin, Heidelberg.

80. Tversky, B. (2003). Structures of mental spaces: How people think about space. Environment and behavior, 35(1), 66-80.

81. Ungar, S., Blades, M., \& Spencer, C. (1993). The role of tactile maps in mobility training. British Journal of Visual Impairment, 11(2), 59-61.

82. Ungar, S., Blades, M., \& Spencer, C. (1995). Visually impaired children's strategies for memorising a map. British Journal of Visual Impairment, 13(1), 27 32.

83. Vecchi, T. (1998). Visuo-spatial imagery in congenitally totally blind people. Memory, 6(1), 91-102. 
84. Vorapatratorn, S., \& Nambunmee, K. (2014). iSonar: an obstacle warning device for the totally blind. Journal of Assistive, Rehabilitative \& Therapeutic Technologies, 2(1), 23114.

85. Vorapatratorn, S., \& Teachavorasinskun, K. (2017, July). iSonar-2: Obstacle Warning Device, the Assistive Technology Integrated with Universal Design for the Blind. In Proceedings of the 11th International Convention on Rehabilitation Engineering and Assistive Technology (p. 22). Singapore Therapeutic, Assistive \& Rehabilitative Technologies (START) Centre.

85. Waller, D., \& Greenauer, N. (2007). The role of body-based sensory information in the acquisition of enduring spatial representations. Psychological research, 71(3), 322-332.

86. Walmsley, D.J., T.F. Saarinen and C.L. MacCabe (1990). Down under or centre stage? The world images of Australian students, The Australian Geographer, vol. 21(2), pp. 164-173.

87. Yusro,M., at al. (2013). SEES: Concept and Design of a Smart Environment Explorer Stick", IEEE HSI 2013

88. Zeng, L., Simros, M., \& Weber, G. (2017, September). Camera-based mobile electronic travel aids support for cognitive mapping of unknown spaces. In Proceedings of the 19th International Conference on Human-Computer Interaction with Mobile Devices and Services (p. 8). ACM.

\section{Appendix Participant Data}

Table 3: Data for participants from France (FR)

Table 4: Data for participants from Italy (IT)

Table 5: Data for participants from Poland (PL)

Table 6: Data for participants from Spain (ES)

Table 7: Data for participants from the United Kingdom (UK)

Abbreviations

Education column:

Account: accountancy

Bac.: baccaleuriat, school leaving/university qualifying examination

Blind (board): boarding school for blind people

Cons: conservatory

Deg: degree

Eng: engineering

Int: integration

MS: mainstream (school)

Psych: psychology

Second, 2nd: secondary school

Spec ed: special education

Special: special school

Stud: student or studies

Uni: university 
O\&M column

Dog or guide dog: guide doc training

Elect or electronic cane: electronic cane training

O\&M: orientation and mobility training

Rehab: rehabilitation 


\begin{tabular}{|c|c|c|c|c|c|c|c|c|c|c|c|c|c|}
\hline & ender & \multicolumn{5}{|c|}{ Age } & \multicolumn{4}{|c|}{ Where live } & \multicolumn{3}{|c|}{ Additional } \\
\hline Male & Female & $16-25$ & $26-40$ & $41-60$ & $61-70$ & $71+$ & Big City & City & Town & Village & EM & $\mathrm{DE}$ & PD \\
\hline 50 & 50 & 9 & 28 & 43 & 17 & 3 & 36 & 37 & 20 & 7 & 5 & 9 & 6 \\
\hline
\end{tabular}

Table 1: Demographic information for sample of 100 participants

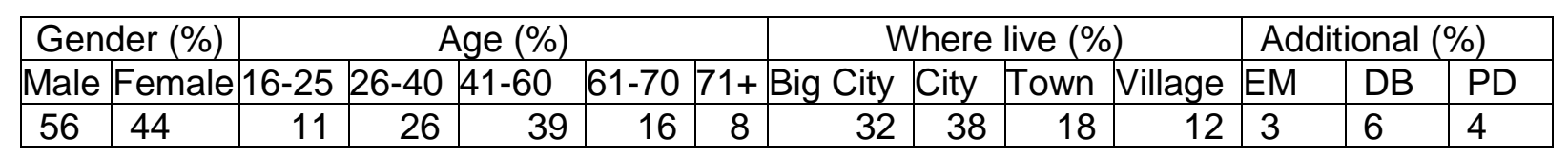

Table 1s: Demographic information for all participants

$E M=$ ethnic minority, $\mathrm{DB}=$ dual sensory impairment/deafblindness, $\mathrm{PD}=$ physically disabled 


\begin{tabular}{|l|l|l|l|l|l|l|l|l|}
\hline \multicolumn{3}{|c|}{ Visual Impairment } & \multicolumn{6}{c|}{ Travel Aid } \\
\hline $\begin{array}{l}\text { Early } \\
\text { blind }\end{array}$ & $\begin{array}{l}\text { Late } \\
\text { blind }\end{array}$ & $\begin{array}{l}\text { Partially } \\
\text { sighted }\end{array}$ & Cane & $\begin{array}{l}\text { Guide } \\
\text { dog }\end{array}$ & $\begin{array}{l}\text { Electronic } \\
\text { cane }\end{array}$ & $\begin{array}{l}\text { Symbol } \\
\text { cane }\end{array}$ & Other & $\begin{array}{l}\text { No } \\
\text { aid }\end{array}$ \\
\hline 24 & 44 & 32 & 58 & 21 & 7 & 3 & 4 & 7 \\
\hline
\end{tabular}

Table 2a, Visual impairment profile and aid use for sample of 100 participants

\begin{tabular}{|l|l|l|l|l|l|l|l|l|}
\hline \multicolumn{3}{|c|}{ Visual Impairment (\%) } & \multicolumn{6}{c|}{ Travel Aid (\%) } \\
\hline $\begin{array}{l}\text { Early } \\
\text { blind }\end{array}$ & $\begin{array}{l}\text { Late } \\
\text { blind }\end{array}$ & $\begin{array}{l}\text { Partially } \\
\text { sighted }\end{array}$ & Cane & $\begin{array}{l}\text { Guide } \\
\text { dog }\end{array}$ & $\begin{array}{l}\text { Electronic } \\
\text { cane }\end{array}$ & $\begin{array}{l}\text { Symbol } \\
\text { cane }\end{array}$ & Other & $\begin{array}{l}\text { No } \\
\text { aid }\end{array}$ \\
\hline 27 & 39 & 35 & 54 & 17 & 5 & 3 & 3 & 18 \\
\hline
\end{tabular}

Table 2a, Visual impairment profile and aid use for all participants 


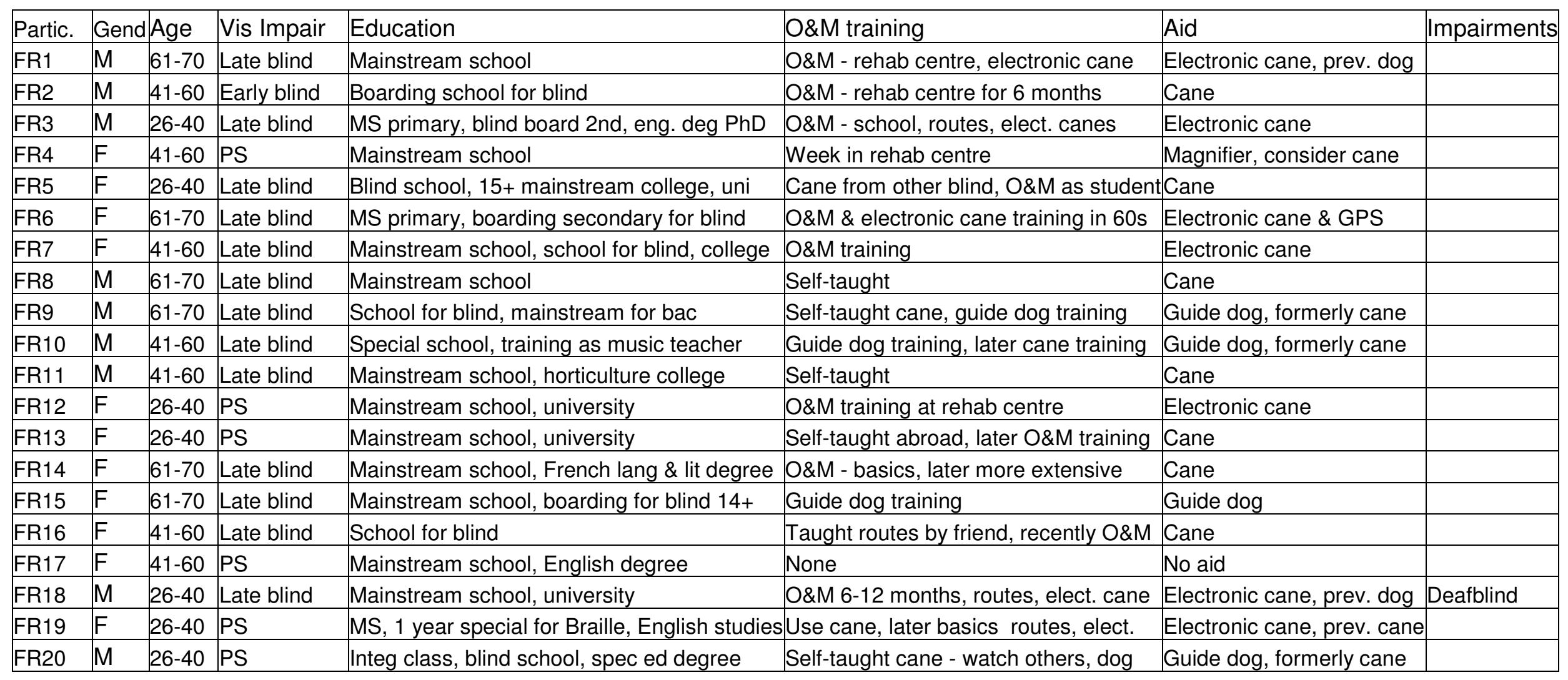

Table 3: Data for participants from France (FR) 


\begin{tabular}{|c|c|c|c|c|c|c|c|}
\hline Partic & Ger & Age & Vis Impair & Education & O\&M training & Aid & Impairments \\
\hline IT1 & $\mathrm{F}$ & $41-60$ & Early blind & School for blind & Self-taught & Cane & \\
\hline IT2 & $\mathrm{F}$ & $51+$ & Early blind & Special school & Guide dog training, 2 hours cane & Guide dog & \\
\hline IT3 & $\mathrm{F}$ & $26-40$ & PS & Mainstream school, university & Self-taught, taught by friends & Cane & \\
\hline IT4 & $\mathrm{F}$ & $16-25$ & Late blind & Mainstream school, currently at university & Blind from birth friend demonstrate. & Cane & \\
\hline IT5 & $\mathrm{M}$ & $41-60$ & Late blind & Mainstream school, university & O\&M training & Cane & \\
\hline IT6 & M & $16-25$ & Early blind & Special school, university & Basics-school, self-taught, friends help & Cane & \\
\hline IT7 & $\mathrm{F}$ & $26-40$ & Late blind & Mainstream school, university & 160 hour O\&M course & Cane & \\
\hline IT8 & $\mathrm{M}$ & $41-60$ & Late blind & University & O\&M training & Cane, formerly guide dog & \\
\hline IT9 & $\mathrm{F}$ & $26-40$ & Early blind & University & O\&M training $(x 2)$, guide dog training & Guide dog, formerly cane & \\
\hline IT10 & $\mathrm{M}$ & $16-25$ & Early blind & 9 years blind boarding school, MS, college & O\&M \& guide dog training, & Cane \& GPS, prev. dog & \\
\hline IT11 & $\mathrm{M}$ & $41-60$ & Early blind & 8 yrs blind school, 2 yrs MS, degree, accoun & tO\&M at school, self-taught routes & Cane & \\
\hline IT12 & $\mathrm{F}$ & $41-60$ & PS & Mainstream school & None & Sometimes symbol cane & \\
\hline IT13 & $\mathrm{M}$ & $71+$ & Early blind & School for blind & Friend show cane, otherwise self-taugh & Cane & \\
\hline IT14 & $\mathrm{M}$ & $26-40$ & PS & Degree, courses in osteopathy \& physiother & None & No aid & \\
\hline IT15 & $\mathrm{F}$ & $16-25$ & Early blind & Engineering degree & O\&M \& guide dog training, & Guide dog, formerly cane & \\
\hline IT16 & $\mathrm{F}$ & $71+$ & Early blind & Boarding school for blind & O\&M theory -school,friends show routes & Cane & \\
\hline IT17 & $\mathrm{M}$ & $41-60$ & Late blind & Physiotherapy college for blind, & Guide dog training & Guide dog, briefly cane & \\
\hline IT18 & $\mathrm{F}$ & $26-40$ & Late blind & College for blind telephonist course & O\&M training self-taught & Cane & \\
\hline IT19 & $\mathrm{F}$ & $41-60$ & Late blind & School for blind & Cane use - more experienced blind & Cane & \\
\hline IT20 & $\mathrm{F}$ & $26-40$ & Late blind & University student in education & O\&M training at 12 & Cane & \\
\hline
\end{tabular}

Table 4: Data for participants from Italy (IT) 


\begin{tabular}{|c|c|c|c|c|c|c|c|}
\hline Partic & \multicolumn{2}{|c|}{ Gend Age } & Vis Impair & Education & O\&M training & Aid & Impairments \\
\hline PL1 & M & $41-60$ & PS & Boarding school for blind, vocational college & $\mathrm{O} \& \mathrm{M}$ training at college & Cane & \\
\hline PL3 & $F$ & $26-40$ & Early blind & Boarding school for blind, degree & O\&M training - school, now learn GPS & Cane & \\
\hline PL5 & $\mathrm{M}$ & $41-60$ & PS & Mainstream school & None & No aid & \\
\hline PL6 & $\mathrm{M}$ & $26-40$ & Early blind & PhD student & O\&M \& guide dog training & Guide dog \& cane & \\
\hline PL7 & $\mathrm{F}$ & $41-60$ & Late blind & Mainstream school, third life university & O\&M training in 2 week rehab & Cane & Deafblind \\
\hline PL10 & $F$ & $26-40$ & Early blind & Blind board, French deg, postgrad diplomas & O\&M training school, later routes & Cane & \\
\hline PL11 & $F$ & $41-60$ & Late blind & Mainstream school, degree in psychology & Self-taught, own system cane used & Cane & \\
\hline PL12 & $\mathrm{F}$ & $16-25$ & PS & MS school, completing sociology degree & O\&M - early secondary \& university & Cane & \\
\hline PL13 & $\mathrm{F}$ & $41-60$ & Late blind & School for blind, part of maths degree & O\&M course, interpreted in own way & Cane & \\
\hline PL14 & $\mathrm{M}$ & $26-40$ & Early blind & Blind boarding, massage and music courses & $\mathrm{O} \& \mathrm{M}$ in primary and secondary schools & sCane & Deafblind \\
\hline PL15 & $\mathrm{M}$ & $26-40$ & Late blind & School for blind & O\&M at school, later successful & Cane & Deafblind \\
\hline PL20 & $\mathrm{M}$ & $61-70$ & Late blind & MS, biotechnology deg, economics MSc & Self-taught & Cane & \\
\hline
\end{tabular}

Table 5: Data for participants from Poland (PL) 


\begin{tabular}{|c|c|c|c|c|c|c|c|}
\hline Partic & Gend & Age & Vis Impair & Education & O\&M training & Aid & Impairments \\
\hline ES1 & $\mathrm{M}$ & $41-60$ & PS & Mainstream school, university without degree & Accompanying person teach routes & Cane & \\
\hline ES2 & $M$ & $41-60$ & Late blind & Mainstream school & O\&M training & Guide dog, formerly cane & \\
\hline ES3 & $M$ & $41-60$ & Late blind & Mainstream school, university & Self-taught \& some correction & Cane & \\
\hline ES4 & $M$ & $41-60$ & PS & MS primary, blind second, now music - cons & O\&M training by ONCE & Cane & \\
\hline ES5 & $\mathrm{F}$ & $26-40$ & PS & Psychology degree & None & Magnifier & \\
\hline ES6 & $\mathrm{F}$ & $16-25$ & Early blind & Mainstream school, bac class at institute & O\&M training & Cane & \\
\hline ES7 & $\mathrm{F}$ & $61-70$ & PS & Mainstream school & O\&M training & Cane, also for support & Physical \\
\hline ES8 & $\mathrm{M}$ & $41-60$ & Late blind & School for blind, university without degree & Brief O\&M, blind students teach cane & Cane & \\
\hline ES9 & $\mathrm{M}$ & $41-60$ & Late blind & School for blind, bac, teacher training & Practice, no formal training & Cane & \\
\hline ES10 & $M$ & $41-60$ & PS & Mainstream school, degree in education & Initially self-taught, later O\&M training & Cane & \\
\hline ES11 & $\mathrm{F}$ & $41-60$ & PS & School for blind, & Brief $O \& M$, no routes & Cane & \\
\hline ES12 & $M$ & $26-40$ & PS & MS school, completing business studies deg & None & No aid & \\
\hline ES13 & $\mathrm{F}$ & $41-60$ & Early blind & School for blind & O\&N training at school & Cane & \\
\hline ES14 & M & $16-25$ & Late blind & Sociology degree, studying political science & O\&M at school, guide dog training & Guide dog, formerly cane & \\
\hline ES15 & $\mathrm{F}$ & $26-40$ & PS & Mainstream school, university & None & No aid & \\
\hline ES16 & M & $41-60$ & Late blind & Mainstream school & O\&M training & Cane & \\
\hline ES17 & $\mathrm{M}$ & $41-60$ & Early blind & School for blind, psychology degree & guide dog training & Guide dog, formerly cane & \\
\hline ES18 & $\mathrm{F}$ & $41-60$ & Late blind & School for blind, law degree & Friends taught cane, week O\&M, guide dog & guide dog, formerly cane & \\
\hline ES19 & $\mathrm{F}$ & $41-60$ & Late blind & School for blind, psychology degree & O\&M training at school guide dog training & Guide dog, formerly cane & \\
\hline ES20 & $\mathrm{M}$ & $41-60$ & Late blind & School for blind & Self-taught, later short course & Cane & \\
\hline
\end{tabular}

Table 6: Data for participants from Spain (ES) 


\begin{tabular}{|c|c|c|c|c|c|c|c|}
\hline Partic. & Gend & Age & Type & Education & O\&M Training & Aid & Impairments \\
\hline UK1 & M & $41-60$ & PS & School \& self-educated & None & Symbol cane & \\
\hline UK3 & $M$ & $61+$ & Late blind & Boarding school \& college for blind & Guide dog, parents taught routes & Guide dog & \\
\hline UK5 & M & $41-60$ & PS & Special school, university & None & No aid & \\
\hline UK6 & M & $41-60$ & Early blind & School and college for blind & Guide dog training & Guide dog & \\
\hline UK7 & $M$ & $26-40$ & Early blind & School for blind, college, university & O\&M, allowed out on routes passed & Cane & \\
\hline UK10 & $\mathrm{F}$ & $41-60$ & PS & School for blind, secretarial course & Guide dog, later long cane training & Guide dog & \\
\hline UK11 & $\mathrm{F}$ & $41-60$ & Early blind & Special school & O\&M at school, guide dog training & Cane & \\
\hline UK12 & $\mathrm{M}$ & $41-60$ & PS & Special school, open university & O\&M at school, explore from school & Cane & \\
\hline UK13 & $\mathrm{M}$ & $41-60$ & Late blind & Mainstream school & O\&M training at rehab centre & Cane & Deafblind \\
\hline UK14 & $\mathrm{M}$ & $61-70$ & Late blind & Mainstream school, Braille course & O\&M training locally & Cane & \\
\hline UK15 & $\mathrm{F}$ & $16-25$ & PS & Blind primary \& college, MS secondary, uni & O\&M - primary, routes - university & Cane \& walking stick & Physical \\
\hline ULK20 & $\mathrm{F}$ & $61+$ & Late blind & University, college for blind & Routes at school, O\&M for year & Cane & \\
\hline
\end{tabular}

Table 7: Data for participants from the United Kingdom (UK) 